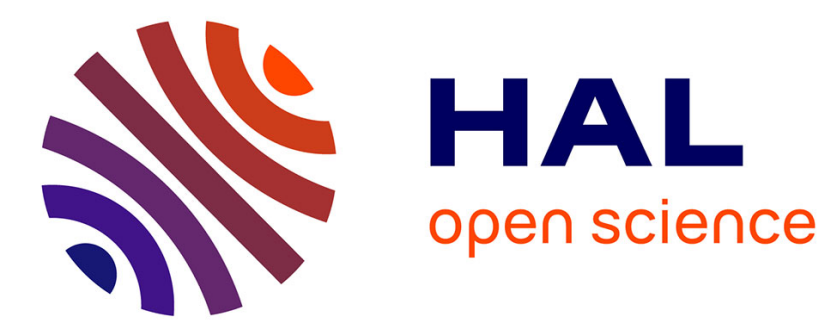

\title{
Fullerene-MWCNT nanostructured-based electrochemical sensor for the detection of Vanillin as food additive
}

\author{
L. Taouri, M. Bourouina, S. Bourouina-Bacha, Didier Hauchard
}

\section{- To cite this version:}

L. Taouri, M. Bourouina, S. Bourouina-Bacha, Didier Hauchard. Fullerene-MWCNT nanostructuredbased electrochemical sensor for the detection of Vanillin as food additive. Journal of Food Composition and Analysis, 2021, 100, pp.103811. 10.1016/j.jfca.2021.103811 . hal-03249666

\section{HAL Id: hal-03249666 \\ https://hal.science/hal-03249666}

Submitted on 10 Jun 2021

HAL is a multi-disciplinary open access archive for the deposit and dissemination of scientific research documents, whether they are published or not. The documents may come from teaching and research institutions in France or abroad, or from public or private research centers.
L'archive ouverte pluridisciplinaire HAL, est destinée au dépôt et à la diffusion de documents scientifiques de niveau recherche, publiés ou non, émanant des établissements d'enseignement et de recherche français ou étrangers, des laboratoires publics ou privés. 


\section{Fullerene-MWCNT nanostructured-based electrochemical sensor for the detection of Vanillin as food additive.}

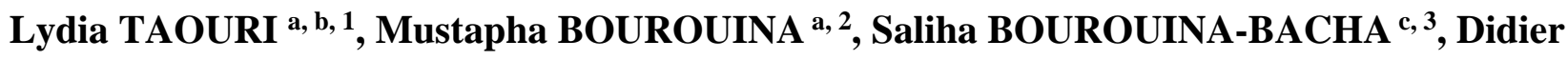 HAUCHARD ${ }^{\mathrm{b}, 4, *}$}

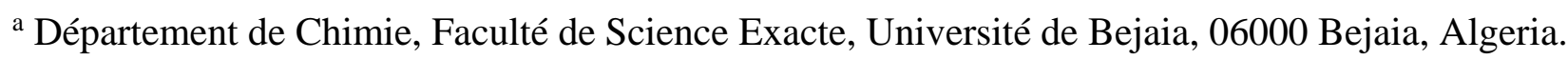

${ }^{\mathrm{b}}$ Université Rennes, Ecole Nationale Supérieure de Chimie de Rennes, CNRS, ISCR (Institut des Sciences Chimiques de Rennes) - UMR 6226, F-35000 Rennes, France.

c Laboratoire de génie de l'environnement, Faculté de Technologie, Université de Bejaia, 06000 Bejaia, Algeria.

Email addresses for authors:

1 nassimalydia35@gmail.com

2 bouryas@yahoo.fr

3 1gebej@yahoo.fr

${ }^{4}$ didier.hauchard@ensc-rennes.fr

* Corresponding author: Didier HAUCHARD

E-mail adresse: didier.hauchard@ensc-rennes.fr

Tel : +33623238044

Affiliation adresse : Université Rennes, Ecole Nationale Supérieure de Chimie de Rennes, CNRS, ISCR (Institut des Sciences Chimiques de Rennes) - UMR 6226, F-35000 Rennes, France. 


\title{
Highlights:
}

- A nanostructured CPE sensor based first on fullerene was developed for electrochemical determination of vanillin.

- Fullerene (FNTs) and MWCNT contribute to the nanostructuration of the carbon paste leading to amplify vanillin electrochemical signal (LD of $34 \mathrm{nM}$ ) with a wide linear range

- The sensitive sensor was validated for the determination of vanillin additive in commercial vanilla sugars without interferences.

- The f-MWCNTs-FNTs/ CPE presented a simple and economical device without any pretreatment.

\begin{abstract}
.
In this paper, a simple, economical, selective and sensitive electrochemical sensor is proposed for the quantification of vanillin (VAN) in real food samples. It consists of a carbon paste electrode (CPE) nanostructured with Fullerene (FNTs) and functionalized multi-walled carbon nanotubes (fMWCNTs). The developed electroanalytical method was performed with cyclic voltammetry after optimization of operating conditions, such as supporting electrolytes, $\mathrm{pH}$ values and accumulation time. After optimization, the nanostructured sensor showed wide linear responses in the range from $5 \times 10^{-8}$ to $9 \times 10^{-6}$ mol.L $\mathrm{L}^{-1}$ for VAN trace levels and from $10^{-5}$ to $10^{-4} \mathrm{~mol} . \mathrm{L}^{-1}$ for higher concentrations, with a low detection limit of $3.4 \times 10^{-8}$ mol. $\mathrm{L}^{-1}$. For concentrations lower than $10^{-5}$ mol.L $\mathrm{L}^{-1}$, VAN was stripped after a previous quick adsorption step (300 s). The f-MWCNTsFNTs/CPE sensor showed a good stability, repeatability and reproducibility (less than $7 \%$ ). This nanostructured sensor was successfully applied to determine VAN concentration as additive in commercial vanilla sugar samples with a satisfactory recovery and a good accuracy $(<6.5 \%)$ in comparison with UPLC/UV control method.
\end{abstract}


Keywords: Vanillin, Vanilla sugar, Fullerene-MWCNT, Electrochemical sensors, Food samples.

\section{Introduction}

Vanillin (4-hydroxy-3-methoxybenzaldehyde) is a polyfunctional compound with an aromatic ring bonded to an aldehyde group, -OH phenolic, and a methoxy group (Isac-García et al., 2016). It is the flavor component of vanilla bean, one of the most popular flavors in the world. According to vanilla and vanillin market report done in 2019, the global VAN demand was 37.286 Tons in 2018 and it is estimate to reach 59.458 Tons by 2024 . This growing demand is due to its wide use in foods, beverages, fragrance, and pharmaceutical products (Research And Markets, 2019). Apart from its flavor properties, this widespread application of VAN is due to their beneficial proprieties, when it is used in low concentrations, offered by their biological and therapeutic activities such as antioxidant, antimicrobial, antimutagenic, hypolipidemic, antisickling and others activities, when it is used in low concentrations (Sinha \& Sharma, 2008).

However, excessive ingestion of VAN have a side effects toward the human health, it can cause potential health problems and aggravate the condition of migraine sufferers, headaches, insomnia, nausea, vomiting, and even liver and kidney problems, apart from the fact that the enticing smell of VAN may cause addiction to such food or beverages (Sivakumar, Sakthivel \& Chen, 2017). Also, skin contact can cause irritation and swelling (inflammation) (Ahmad et al., 2020). In addition, VAN in high concentrations ( $\mathrm{mM}$ range) has been described as a cytotoxic agent against many cell lines, including mouse fibroblast 3 T3 cells, human ovarian carcinoma A2780-SC1 cells, human colorectal carcinoma HT-29 cells, HepG2 cells, human cervical carcinoma HeLa cells, and human colorectal carcinoma SW480 cells (Bezerra et al., 2016).

An acceptable daily intake (ADI) of $10 \mathrm{mg} / \mathrm{Kg}$ for VAN has been set by the Joint FAO/WHO Expert Committee on Food Additive (JECFA) in 1967 and later confirmed in its 2001 re-evolution as flavoring. This value of ADI has been also agreed by the European Union (Younes et al., 2018). Toxic effects are observed when the intake exceeds $75 \mathrm{mg} / \mathrm{Kg}$ (Ramesh \& Muthuraman, 2018). Therefore, the monitoring of the level of VAN is necessary not only to control the quality of the product but also to ensure the protection of the human health.

Several analytical techniques have been proposed for the quantitative determination of VAN such as high performance liquid chromatography with a fluorescence detector (Nasuno, et al., 2020), capillary electrophoresis (Shu et al., 2016), optical fluorescence (Dur an \& Contento, 2015) and 
colorimetric assay (Zhao et al., 2018). However, these techniques are often complicated, expensive, require qualified personnel and often very long analysis time.

However, electrochemical techniques constitute a promising alternative because of their simplicity, sensitivity, inexpensiveness, fast response time and their capacity to miniaturize (Manasa et al., 2019; Karimi-Maleh et al., 2020). Especially, the use of carbon paste electrode (CPE) has received the highest attention due to its simple preparation procedure, homogeneity, low background current, cost-effectiveness and adaptability to modifications (Bojdi, 2016).

In the literature, various types of electrodes and modified electrodes have been reported recently for the detection of VAN based on carbon materials as graphite (Dilgin, 2019), carbon black (Kutty et al., 2019), carbon nanotubes modified with gold nanoparticles (Ceylan Koçak \& Ulubay Karabiberoğlu, 2018), graphene (including reduced graphene oxide and graphene oxide) containing metal nanoparticles (Gao et al., 2018; Ning et al., 2018; Mohan, 2019). Moreover, others sensors involve surface modification by metal oxide or metal nanoparticles or by using other material such as cetyltrimethylammoniumbromide (CTAB) (Durán et al., 2018; Murtada et al., 2018; Erady et al., 2020). However, the most of them need a complicated procedure of surface functionalization and/or do not aim the determination of the real VAN concentration in food samples.

Recent work revealed that the Fullerene, the third allotropes of carbon which were discovered in 1985 (Kroto, 1987), attracted enormous attention from physicists, chemists and material designers due to its unique tree-dimensional nanostructure, remarkable electrochemical, electrocatalysis and photocatalysis proprieties. Especially, Fullerene possess high electroactive surface area, good electronic conductivity, high chemical stability. These new discovered carbon allotropes have multiple redox states and an ability to accept and transport easily electrons, which leads to the possibility of functionalization, signal mediation and others remarkable characteristics (Sherigara et al., 2003; Pan et al., 2020; Pilehvar \& Wael, 2015). The use of Fullerene as electrode modifier material is still recent and considered as new and attractive element in the development of sensors and biosensors.

In the recent years and with the emergence of nanotechnology, the scientists are focusing on arranging atoms and molecules in different shapes and patterns by self-assembly in order to recognize their properties (Rao et al., 2016). In this context, novel various form of fullerene have been investigated such as fullerene nanowhiskers ( $\left.\mathrm{C}_{60} \mathrm{NWs}\right)$, fullerene nanofibers (FNFs) and fullerene nanotubes (FNTs). In our study, we have interested to the use of FNTs as material in the conception of a nanostructured sensor. The fullerene nanotubes (FNTs) are fullerene that grow spontaneously into the form of tubes with a single crystalline, polycrystalline or amorphous structures (Miyazawa, 2009). 
Carbon nanotubes are considered as graphite sheets that are rolled up into cylindrical shapes, which has received a great attention due to its exceptional optical, mechanical, electronic and thermal properties. Their electrocatalytic properties have driven the researchers to explore these nanomaterials in electrochemical sensing (D'Souza et al., 2017).

In addition, fullerene and multi-walled carbon nanotube composite was used for the first time by $\mathrm{H}$. Zhang and his team to modify a glassy carbon electrode and studied the direct electrochemical behavior of hemoglobin $(\mathrm{Hb})$ in aqueous solutions. Their study demonstrated that MWCNTs-FNTs films nanocomposite were more effective in facilitating the direct electron transfer of hemoglobin $\mathrm{Hb}$ ) than MWCNTs films. Furthermore, the heterogeneous electron transfer rate constant ks of $\mathrm{Hb}$ calculated on MWCNTs-FNTs composite film was almost an order of magnitude larger than that on MWCNTs film (Zhang et al., 2006). In the same case of application of MWCNTs-FNTs composite like electrochemical sensor, H. Zhu et al. have developed a MWCNTs-FNTs electrode for the sensitive detection of dopamine in presence of ascorbic acid (Zhu et al., 2009). M. MazloumArdakani et al. have fabricated an electrochemical sensor based on fullerene-functionalized carbon nanotubes composite for the sensitive and simultaneous determination of the levodopa and acetaminophen (Mazloum-Ardakani et al., 2016). Both works investigated the performance of FNTs and multi-walled carbon nanotubes on the responses of the sensor. But, as our knowledge, no sensor based on fullerene is available for the quantification of VAN.

In the present work, we describes the simple design and the performance of a nanostructured and sensitive f-MWCNTs-FNTs modified carbon paste electrode as a new electrochemical sensor for the quantification of VAN in real samples of commercial vanilla sugar and our method was validated in comparison to UPLC/UV control method. The newly fabricated electrode offers several advantages over other techniques used for the determination of VAN, including the simplicity of the sensor preparation, low cost, rapidity with very good analytical characteristics as selectivity, high sensitivity and low detection limits. Moreover, the most important advantage is the feasibility to the determination of the real VAN concentration in real matrices, with any pretreatment by following a simple procedure.

\section{Experimental}

\subsection{Reagents}

Graphite powder $(4 \mu \mathrm{m})(99,5 \%)$ were purchased from Prographite $\mathrm{GmbH}$; Multi-walled carbon nanotubes $(1.5 \mu \mathrm{m})(90 \%)$ from GoodFellow (NC006090); Fullerene nanotube multi-walled (20 $\mathrm{nm}, 5-20 \mu \mathrm{m})(95 \%)$, Paraffin oil and VAN ( $\geq 98 \%)$ and acetic acid ( $\geq 99 \%)$ from Fulka 
Chemika; phosphoric acid (85\%) and Boric acid (99.5\%) from Acros Organics. Nitric acid (70\%), sulfuric acid (98\%), sodium hydroxide ( $\geq 98)$ and potassium hexacyanoferrate (III) ( $\geq 99)$ were purchased from Sigma-Aldrich. All aqueous solutions were prepared by deionized water 10 to 15 $\mathrm{M} \Omega . \mathrm{cm}$ at $25^{\circ} \mathrm{C}$.

\subsection{Apparatus}

The voltammetric measurements were carried out with an Autolab PGSTAT20 Metrohm potentiostat / galvanostat, controlled by a computer equipped with NOVA 2.1.2 software for controlling analysis and data processing. A conventional three electrodes system was used throughout this study. The working electrode was f-MWCNTs-FNTs/ CPE (diameter $1.6 \mathrm{~mm}$ ), the auxiliary and reference electrode were respectively a platinum wire and a $\mathrm{Ag} / \mathrm{AgCl}(3 \mathrm{M} \mathrm{KCl})$ as reference electrode. All measurements were performed at room temperature. The surface morphology was characterized by scanning electron microscopy (SEM) (JEOL JSM-7100F, Detector EDS Oxford Instrument $50 \mathrm{~mm}^{2}$ ) from CMEBA center of ISCR-CNRS6226 at Rennes, France. The analytical measurements were performed with Ultra performance Liquid Chromotography (UPLC) which was conducted on ACQUITY HClass Waters model including Acquity UPLC R BEH C18 $1.7 \mu \mathrm{m}, 2.1 \times 100 \mathrm{~mm}$ column thermostated at $30^{\circ} \mathrm{C}$ and equipped with PDA e $\lambda$ detector. An elution gradient was used by using two mobile phases, A: ultra-pure water, $10 \%$ Acetonitrile and $0.1 \%$ formic acid and $\mathrm{B}$ : acetonitrile with $0.1 \%$ in a flow rate of 0.4 $\mathrm{mL} \cdot \mathrm{min}^{-1}$. The injected volum was $10 \mu \mathrm{L}$ and the chromatograms were registred at $230 \mathrm{~nm}$.

\subsection{Preparation of the functionalized multi-walled carbon nanotubes (f-MWCNTs)}

The preparation of f-MWCNTs was inspired by the method followed by (Baykal et al., 2013) with some modification in the procedure: $0.5 \mathrm{~g}$ of MWCNTs was added in $15 \mathrm{~mL}$ concentrated sulfuric acid and $5 \mathrm{~mL}$ concentrated nitric acid. The mixture was stirring vigorously for 24 hours. Then, 100 $\mathrm{mL}$ of distilled water was added to the previous solution and stirring for another hour. After that, the suspension was filtered and washed 2 times with distilled water and dried at room temperature for a night. Afterwards, the product was washed again with distilled water for 3 times. At the end, the f-MWCNTs were dried at $70^{\circ} \mathrm{C}$ for 18 hours.

\subsection{Fabrication of the proposed sensor}

The functionalized multi-walled carbon nanotubes/FNTserene composite modified carbon paste electrodes (f-MWCNTs-FNTs/ CPE) was prepared by thoroughly mixing of graphite, f-MWCNTs, FNTs with paraffin oil at ration $(55 \% ; 20 \% ; 10 \% ; 15 \%)$, respectively, in agate mortar with pestle. All the components were homogenized to obtain a paste. The latter was introduced and compacted 
into the cylindrical cavity $(1.6 \mathrm{~mm}$ diameter and $3 \mathrm{~mm}$ depth $)$ at the extremity of the electrode body and smoothed on a clean paper until it had a uniform surface. A wire of copper passing through the electrode support ensured the electrical contact with the paste.

In order to compare the performance of the developed sensor and to improve the impact of the introducing of FNTs in the matrix of the electrode, we have also prepared CPE (85\% of graphite) and f-MWCNTs/ CPE, were the composition of the graphite and f-MWCNTs was 55\% and 30\%, respectively. The portion of the binder (paraffin oil) was been maintaining at $15 \%$. This percentage was chosen to have a paste with good mechanical strength, consistent, which does not crumble and with sufficient conductivity. The steps of the preparation of f-MWCNTs-FNTs/ CPE are illustrated in Fig.1.

\section{Insert Figure 1.}

\subsection{Electrochemical measurements}

The electrochemical behavior of different electrodes was investigated in an electrochemical cell containing a platinum wire as auxiliary electrode and an $\mathrm{Ag} / \mathrm{AgCl}(3 \mathrm{M} \mathrm{KCl})$ electrode as reference electrode. The three electrodes were immersed in $20 \mathrm{~mL}$ BR solution $\left(0.04 \mathrm{~mol} . \mathrm{L}^{-1}\right)$ at $\mathrm{pH}=7$. Then, an appropriate micro-volume of VAN concentrated solution was added into the cell. The i E curves were recorded by cyclic voltammetry, in the potential range of -0.2 to $1.2 \mathrm{~V}$ at a scan rate of $20 \mathrm{mV} . \mathrm{s}^{-1}$, after 5 minutes of constant stirring at room temperature. All electrochemical measurements were performed inside a Faraday cage in order to minimize the contribution of background noise to the analytical signal.

\subsection{Preparation of the commercial food samples}

Sugar vanilla samples of four different commercial brands were purchased from a local supermarket. Their packaging indicated just the ingredients without indications of quantities: sugar, cornstarch, VAN and exhausted vanilla pods. The sample solutions were prepared by the following procedure. About $5 \mathrm{mg}$ of each samples was dispersed in $100 \mathrm{~mL}$ of ultra-pure water. Then, sonicated for $30 \mathrm{~min}$ in ultrasonic bath. After filtration with syringe filter $(0.45 \mu \mathrm{m}), 1 \mathrm{~mL}$ of each sample was transferred in the voltammetric cell containing $19 \mathrm{~mL}$ of the supporting electrolyte (BR Solution, $\mathrm{pH}=7$ ), for voltammetric analysis. Each solution was analyzed in the day of preparation according to the same procedure developed for the synthetic solution. In parallel, the filtrated solutions of sugar samples were analyzed by UPLC/UV as control method after the realization of a calibration curve $\left(.0 .2-15 \mathrm{mg} . \mathrm{L}^{-1}\right)$ by integrating the peak chromatogram at $\operatorname{tr}=2.03 \mathrm{~min}(230 \mathrm{~nm})$. 


\section{Results and discussions}

\subsection{Characterization of the materials of electrode}

The morphology and particle size analysis of the components of the f-MWCNTs-FNTs modified electrode were studied by SEM technique. The graphite appears as particles with flake shaped structure ranging in size from lower than $4 \mu \mathrm{m}$ diameter and lower than $1 \mu \mathrm{m}$ thick. (Fig.2-A). While fullerene wires showed their nanometrical size in diameter (estimated from 15 to $20 \mathrm{~nm}$ ) they have a tube shaped structure and are wound into a ball and appear as balls of wood with a diameter

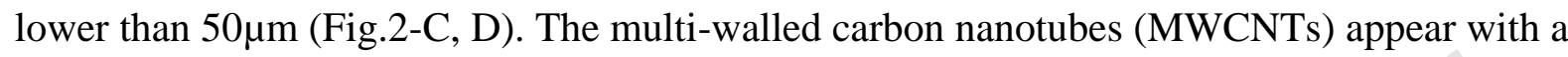
spaghetti shaped structure less compacted than FNTs and with a diameter slightly weaker 10-15 nm (Fig.2-E). The functionalization of MWCNTs as proposed in section 2.3 provided a more disperse structure with lower length of the nanotubes in comparison with the non-functionalized one (Fig. 2F). For the CPE modified electrode, in the (Fig. 2-B), it can be seen that in the mixture of of $\mathrm{f}-$ MWCNTs, FNTs and graphite are linked in a way to avoid the stacking of graphite platelet and to promote the accessibility to the analyte in their surfaces and improve the charge transfer in the paste. Globally, the f-MWCNTs-FNTs electrode showed a uniform and nanostructured surface which could yield to large surface area and improve the characteristics of the pervious fabricated sensor.

\section{Insert Figure 2.}

\subsection{Chronoamperometry (CA) studies}

Chronoamperometric measurement was performed to determine active surface area of the prepared electrode. This study was recorded in the presence of $1 \times 10^{-3} \mathrm{~mol} . \mathrm{L}^{-1}$ of potassium hexacynoferrate (III) as the redox probe in the condition of diffusion control for the current obtained in CA. In this case, the current-time response is described by the Cottrell equation (Bard \& Faulkner, 2001):

$\mathrm{i}=\frac{\mathrm{nFAD}{ }^{1 / 2 C^{*}}}{\pi^{1 / 2 t^{1 / 2}}}$

Where $\mathrm{A}$ is the active area of the electrode, $\mathrm{C}^{*}$ is the initial concentration of ferrocyanide, $\mathrm{D}$ the diffusion coefficient of ferrocyanide which is well known to be $6.22 \times 10^{-6} \mathrm{~cm}^{2} . \mathrm{s}^{-1}$ (Denuault et al., 1991) in aqueous electrolyte and the other parameters have their typical significances.

The electrochemical active area of the sensor was estimate to be $0.14 \mathrm{~cm}^{2}$ from the slope of the linear regression line of current density versus square root of time. While, the geometric surface of the $2 \mathrm{~mm}$ diameter electrode was calculated to be $0.02 \mathrm{~cm}^{2}$ considering the cross section of the 
cavity. Thus, the nanostructuration of the carbon paste sensor gives a greater specific surface than the geometric one and enables the access of the cell solution to a larger surface of graphite particles by avoiding their stacking.

\subsection{Electrochemical impedance spectroscopy (EIS) studies}

EIS is a sensitive electrochemical technique to characterize the electrical impedance of the interface between electrode and electrolyte. This procedure also give information about the change in conductance or impedance of an electrode/electrolyte interface during its modifications. EIS diagram named Nyquist plot have a semicircle part at higher frequencies corresponding to the limiting by electron transfer process and a linear part at lower frequencies correlating with the diffusionally controlled region (Randviir \& Banks, 2013; Pajkossy \& Jurczakowski, 2017).

The impedance spectra were recorded for the electrodes of CPE and f-MWCNTs-FNTs/CPE in electrolyte solution containing $10^{-3} \mathrm{~mol} . \mathrm{L}^{-1}$ of potassium hexacynoferrate (III) in the frequency range from $10^{-3}$ to $10^{+5} \mathrm{~Hz}$ by using a sinusoidal excitation signal (sine signal) with amplitude of $0.01 \mathrm{~V}$ (Fig.3).

The CPE showed a semicircle with a large diameter and charge transfer resistance of $16.7 \mathrm{~K} \Omega$. The nanostructuration of CPE leads to the decrease of the semicircle diameter at $6.81 \mathrm{~K} \Omega$, which indicated a lower charge transfer resistance (reduction by a factor of 2.5). This is ascribed to the nanostructuration by f-MWCNT and FNTs, which reduce charge transfer resistance and therefore increase the electron transfer kinetic. The linear parts for the lowest frequencies are not depending on the composition of the carbon paste electrode (same slope). This is consistent with the diffusional controlled process identical in the two cases.

\section{Insert Figure 3.}

\subsection{Voltammetric Behavior of VAN at f-MWCNTs-FNTs/ CPE}

In order to evaluate the performance and the sensitivity of developed f-MWCNTs-FNTs/ CPE sensor toward the detection of VAN, voltammetric curves $(\mathrm{CV})$ were recorded for CPE, $\mathrm{f}-$ MWCNTs and f-MWCNTs-FNTs nanostructured modified CPE in presence of $10^{-5} \mathrm{~mol}^{-1} \mathrm{VAN}$ at the scan rate of $20 \mathrm{mV} . \mathrm{s}^{-1}$ in BR buffer at $\mathrm{pH}=7$ as the supporting electrolyte-(Fig.4). The $\mathrm{CV}$ of $\mathrm{CPE}$, in the presence of VAN shows a not well defined anodic peak $(2.3 \mu \mathrm{A})$ at around $+0.6 \mathrm{~V}$. The incorporation of f-MWCNTs in the paste (30\%) leads to enhance the peak current of VAN oxidation $(6.3 \mu \mathrm{A})$. The addition of FNTs $(10 \%$, by replacing a part of MWCNTs and maintaining 
all the carbon nanotubes to $30 \%$ ), improves notably the peak intensity. Therefore, the anodic peak current obtained with the nanostructured modified electrode $(9.2 \mu \mathrm{A})$ is 4 times higher than with CPE. The combination of FNTs and f-MWCNTs facilitate the accessibility of VAN to graphite particles and the electron transfer at the electrode material.

\section{Insert Figure 4.}

\subsection{Effect of pH}

The effect of the electrolyte $\mathrm{pH}$ on the oxidation of $10^{-6} \mathrm{~mol} . \mathrm{L}^{-1}$ VAN was investigated using $\mathrm{CV}$ measurements in the $\mathrm{BR}$ solution in the $\mathrm{pH}$ range from 5 to 9 at $18^{\circ} \mathrm{C}$.

As can be seen in Fig. 5-A, the oxidation peak current of VAN is depending on the $\mathrm{pH}$ value and increases with increasing $\mathrm{pH}$ until it reaches the maximum at $\mathrm{pH}=7$, and then decreases with higher $\mathrm{pH}$ values. The optimized $\mathrm{pH}$ corresponding to the higher peak current was 7 , indicating that protons are involved in the reaction of VAN oxidation. Moreover, as the pKa of VAN was equal to 7.4 at $25^{\circ} \mathrm{C}$ (Serjeant \& Dempsey, 1979), this result indicated that the analyte was preferentially adsorbed in the neutral form.

In addition, it is found that the values of peak potential shift to lower values with the increase of $\mathrm{pH}$, as shown in Fig.5-B. Thus, the peak potential is linearly depended on the $\mathrm{pH}$ according to the following equation:

$\mathrm{Ep}(\mathrm{V})=-0.0542 \mathrm{pH}+1.01(\mathrm{R}=0.993)$. A shift of typically $54.2 \mathrm{mV}$ per $\mathrm{pH}$ unit is approximately close to the theoretical value of $57.6 \mathrm{mV}$ per $\mathrm{pH}$ unit at $18^{\circ} \mathrm{C}$ (Bard \& Faulkner, 2001), and it demonstrates that the electron-transfer process during the oxidation of VAN, involved an equal number of protons and electrons (two electrons and two protons take part in the oxidation process), which is in agreement with that obtained before by different authors (Ceylan Koçak \& Ulubay Karabiberoğlu, 2018; Abbasghorbani, 2017; Kalaiyarasi et al., 2017).

\section{Insert Figure 5.}

\subsection{Effect of potential scan rate}

Cyclic voltammograms of $10^{-6}$ mol. $\mathrm{L}^{-1}$ VAN at f-MWCNTs-FNTs modified paste electrode were recorded for different potential scan rates and the variation of the peak current in function of the scan rate are presented in Fig. 6-A. It can been seen that, in presence of a low VAN concentration, the oxidation peak current of VAN increases linearly with the scan rate in the range from 0.005 to $0.08 \mathrm{~V} . \mathrm{s}^{-1}$, with a linear relationship $\mathrm{I}_{\text {pic }}=7.80 \times 10^{+4} \vartheta+5.35$ and a correlation coefficient of $\mathrm{R}^{2}=0.995$. This indicates that the oxidation of VAN is not controlled by the diffusion of VAN but 
by an adsorption-controlled process for this low VAN concentration. This adsorption step will provide sensibility for the developed sensor and lead to a low detection limit.

\subsection{Effect of accumulation time}

Accumulation time for the electrochemical measurements is an important parameter that affects the current response of $10^{-6}$ mol. $\mathrm{L}^{-1}$ VAN at f-MWCNTs-FNTs/ CPE. As shown in Fig. 6-B, the oxidation peak current of VAN gradually increased with increasing accumulation time from 30 to $360 \mathrm{~s}$, and reached the maximum current response at $300 \mathrm{~s}$ then remains almost constant at longer accumulation times. For practical purposes, a $300 \mathrm{~s}$ accumulation time is sufficient and used for a determination of VAN.

\section{Insert Figure 6.}

\subsection{Calibration curves and detection limit}

In order to evaluate the linear range and detection limit of the f-MWCNTs-FNTs/CPE, the quantitative analysis of VAN concentration using the developed sensor was performed by cyclic voltammetry under the optimized conditions (Fig. 7-A).

The intensity of the oxidation peak current of VAN increases with the VAN concentration. The calibration curve for peak current (Ip) versus [VAN] (Fig. 7-B \& 7-C) indicates that there are two clearly defined linear ranges:

- from $5 \times 10^{-8}$ to $9 \times 10^{-6}$ mol. $\mathrm{L}^{-1}$ with a linear regression equation of $\mathrm{I}_{\mathrm{p}}=3.89 \times$ $10^{+5}[\mathrm{VAN}]+0.522, \mathrm{R}^{2}=0.999$

- from $1 \times 10^{-5}$ to $1 \times 10^{-4}$ mol. $\mathrm{L}^{-1}$ with a linear regression equation of $\mathrm{I}_{\text {pic }}=7.80 \times$ $10^{+4}[\mathrm{VAN}]+5.35, \mathrm{R}^{2}=0.995$

These two concentration ranges indicate that the VAN oxidation is not controlled by the same process.. For the lowest concentrations (below $10^{-5} \mathrm{~mol} . \mathrm{L}^{-1}$ ), the peak current is controlled by an adsorption step of VAN at the electrode surface (as seen in 3.6 section) which provides an interesting sensibility. For highest concentration $\left(>10^{-5} \mathrm{~mol} . \mathrm{L}^{-1}\right)$ the peak current is controlled by the diffusion of VAN.

The detection limit of the proposed method is found to be $3.4 \times 10^{-8} \mathrm{~mol}$. $\mathrm{L}^{-1}$, calculated from the formula:

$$
\mathrm{LD}=3.3 \times \frac{\mathrm{SD}}{b}
$$

Where $S D$ the standard deviation of the linear regression solution and $\mathrm{b}$ is the slope of the linear regression (Shrivastava \& Gupta, 2011). 


\section{Insert Figure 7.}

As can be seen on Table 1, the f-MWCNTs-FNTs/CPE prepared sensor shows a low detection limit and a large linear concentration range compared to those reported in the literature (Ceylan Koçak et al., 2018; Dilgin et al., 2019; Chen et al., 2019; Fu et al., 2020; Raril et al., 2020; Raril et al., 2020; Tabanligil Calam, 2020).

Thus, the proposed electrochemical sensor show very good performances by just using a few cost electrodes materials in comparison with some reports that give practically similar analytical characteristics. It is also distinguished by the simplicity and the quick modification step of the electrode, which make it an attractive sensor for the monitoring of the quality analysis of food products containing VAN as additive.

\section{Insert Table 1.}

\subsection{Repeatability and reproducibility of f-MWCNTs-FNTs/ CPE}

The repeatability of the nanostructured carbon paste electrode is carried for three different concentrations $\left(10^{-7}, 10^{-6}\right.$ and $\left.10^{-5} \mathrm{~mol} . \mathrm{L}^{-1}\right)$, in order to cover the two adsorption and diffusion control processes. Three successive measurements were carried out for each concentration by using the same sensor. The resulted values of relative standard deviation (RSD) are presented in Table 2A indicating an acceptable repeatability (less than 7\%). Furthermore, reproducibility is checked by recording the current response of three concentrations at two independent sensor prepared with the same procedure and paste composition. As one can see from Table 2-A, the obtained values of RSD are lower than $6 \%$ and good accuracy could be achieved especially for the lowest concentration $\left(10^{-7}\right.$ mol. $\left.\mathrm{L}^{-1}\right)$ with $\mathrm{RSD}$ value of $2.1 \%$.

\subsection{Selectivity and stability of f-MWCNTs-FNTs/ CPE}

The selectivity of the f-MWCNTs-FNTs/CPE is tested using the CV technique in adsorption control process by performing the response of $10^{-6} \mathrm{~mol} . \mathrm{L}^{-1}$ of VAN in the presence of some potential interfering substances at similar concentrations.

The presence of sugars such as glucose and saccharose have no noticeable effect on peak intensity (variation $<5 \%$; Fig.8). This indicates that it is unlikely to have matrix effects for the analysis of vanilla sugars. The greater effects were observed for caffeine and uric acid with a variation not exceeding $22 \%$. These low variations in the oxidation current response of VAN were likely due to the presence of a similar electroactive functional group. In order to preserve the selectivity for VAN 
for samples containing these interferents, it is preferable to dilute samples to minimize their concentrations and to analyze low concentrations of VAN with an adsorption step to guarantee the specificity of the response. Indeed, for any target molecules to be absorbed on the surface of the electrode, they must have sufficient affinity for the sensor material to adsorb selectively in order to be detected. Vanillin has a hydrophobic character $(\log \mathrm{Kow}=1.37)$ in comparison with the hydrophylic tested interferents $(\log$ Kow $<0)$. This is probably not the own reason that could explain this selectivity. In fact, the possibility of charge on molecule, in relation with pKa value and $\mathrm{pH}$ of electrolyte could influence molecule adsorption on carbon paste. For vanillin $(\mathrm{pKa}=7.4)$, it adsorbed preferentially in neutral form while others studied molecules such uric acid and ascorbic acid ( $\mathrm{pKa}<5.5)$ are charged negatively in PBS electrolyte $(\mathrm{pH}=7)$, and this could be unfavorable to their adsorption. Other interferents such sulfate and chloride anion, $\mathrm{Fe}^{3+}$ ion, oxalate and acetate, show negligible impact on current responses. Therefore, the results demonstrate the possibility to obtain a high selectivity of f-MWCNTs-FNTs/CPE toward VAN and permit feasibility for real food sample analysis of VAN.

\section{Insert Figure 8.}

Moreover, the stability of f-MWCNTs-FNTs/ CPE sensor is evaluated using CV for VAN

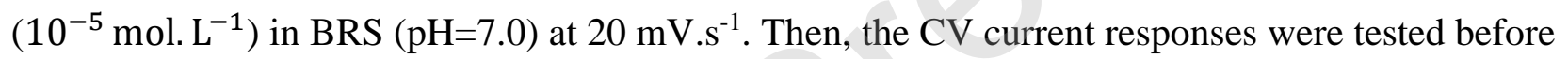
and after storage at $25^{\circ} \mathrm{C}$ during 10 days without following a specific procedure and the results are shown in Fig.9. It appears that the electrode remains stable during 7 days storage, with a slight decreasing of peak current lower than 5\%. The variation doesn't exceed $10 \%$ after 10 days indicating a good stability of the sensor.

\section{Insert Figure 9.}

3.11 Vanilla sugar analysis

The performance and the feasibility of the developed sensor to quantify VAN are evaluated by using the f-MWCNTs-FNTs/ CPE in four real sugar vanilla samples from different commercial brands for which the manufacturers don't indicate the VAN proportion in composition. The concentration of VAN in the samples was determinate by standard addition method by successive addition of known VAN amounts $\left(2 \times 10^{-6} ; 4 \times 10^{-6}\right.$ and $6 \times 10^{-6} \mathrm{~mol}$. $\left.\mathrm{L}^{-1}\right)$ in the electrochemical cell containing the electrolyte in which the sugar sample was dissolved (as described in Section 2.6). This operation was achieved in triplicate for each sugar sample. In order to validate the results, high performance liquid chromatography (UPLC/UV) was used as a control method to determine the content of VAN in these samples. The results obtained with the proposed 
method and the control analytical method are compiled in Table 2-B. The contents of VAN for the different samples were between 2.9 and $4.8 \mathrm{mg}$ of VAN per g of sugar (lower than $0.5 \%$ ) with repeatability comparable to that observed previously in synthetic solutions (see section 3.9). The results obtained with the developed sensor were in accordance with those obtained by the UPLC/UV control method (recovery values between 100-107\% for the different samples). We can concluded that the constituents of vanilla sugar do not interfere in the VAN analysis. Therefore, the proposed nanostructured composite modified carbon paste electrode (f-MWCNTsFNTs/CPE) is able to control VAN as ingredient after simple dissolution of vanilla sugar samples without extraction procedure. This proposed electroanalytical method demonstrates a good accuracy of the proposed sensor and its feasibility in food sample analysis.

\section{Insert Table 2.}

\section{Conclusion}

The proposed sensor for the detection of vanillin was fabricated using a carbon paste electrode modified with fullerene and functionalized multi-walled carbon nanotubes. The excellent proprieties of the nanostructured carbon paste enhance surface area and improve considerably the electrons transfer that lead to a remarkable electrochemical and analytical performances with a wide linear range, lower detection limit, excellent sensitivity, good stability and satisfactory repeatability and reproducibility. The proposed modified electrode was successfully applied to the determination of vanillin in commercial sugar vanilla samples with a satisfactory recovery in comparison of the control UPLC/UV analytical method and without any specific preparation of the samples, just by dissolving the sample in the BRS electrolyte. Hence, the so-designed sensor could be a promising and suitable devise to quantify and monitory vanillin as ingredient in commercial food.

\section{Credit authorship contribution statement:}

Lydia TAOURI: conceptualization, methodology, validation, formal analysis, investigation, writing- original draft, visualization. Mustapha BOUROUINA: conceptualization, methodology, resources, writing- review \& editing, supervision. Saliha BOUROUINA-BACHA: writing- review \& editing. Didier HAUCHARD: conceptualization, methodology, validation, resources, writingreview \& editing, supervision.

All authors have read and agreed to the published version of the manuscript.

\section{Conflict of interest}

The authors declare no conflict of interest.

\section{Acknowledgements}


The authors acknowledge the financial support of the Algerian Ministry of Education and Scientific Research and Campus France program under grant agreement PROFAS B+, and express their grateFNTsy acknowledgements to F. Gouttefangeas from the CMEBA center of ISCR-CNRS 6226 for the MEB analysis and to C. Gardin from CIP team of ISCR-CNRS 6226 for chromatographic analysis. 


\section{References}

Abbasghorbani, M. (2017). Electrochemical Determination of Vanillin in Food Samples Using MgO/SWCNTs-ionic Liquid Modified Electrode, International Journal of Electrochemical Science, 12 (12), 11656-11665.

Ahmad, H., Khera, R. A., Hanif, M. A., Ayub, M. A. \& Jilani, M. I. (2020). Chapter 48: Vanilla. In Hanif, M. A., Khun, M. M., Nawaz, H. \& Byrne H. J. (Eds) Medicinal Plants of South Asia, Novel sources for drug discovery, 657-669.

Altunay, N. (2018). Development of vortex-assisted ionic liquid-dispersive microextraction methodology for vanillin monitoring in food products using ultraviolet-visible spectrophotometry, LWT - Food Science and Technology, 93, 9-15.

Bard, A. J. \& Faulkner, L. R. (2001). Electrochemical Methods: Fundamentals Applications, $\left(2^{\text {nd }}\right.$ Eds), New York: Wiley, 87.

Bojdi, M. K., Behbahani, M., Omidi F. \& Hesam, G. (2016). Application of a novel electrochemical sensor based on modified siliceous mesocellular foam for electrochemical detection of ultratrace amounts of mercury ions, New Journal of Chemistry, 40, 4519-4527.

Baykal, A., Senel, M., Unal, B., Karaoğlu, E., Sözeri H. \& Toprak, M. S. (2013). Acid Functionalized Multiwall Carbon Nanotube/Magnetite (MWCNT)-COOH/ $/ \mathrm{Fe}_{3} \mathrm{O}_{4}$ Hybrid: Synthesis, Characterization and Conductivity Evaluation, Journal of Inorganic and Organometallic Polymers, 23, 726-735.

Bezerra, D. P., Soares, A. K. N. \& De Sousa, D. P. (2016). Overview of the role of vanillin on redox status and cancer development, Oxidative Medicine and Cellular Longevity, 9.

Ceylan Koçak, C. \& Ulubay Karabiberoğlu, S. (2018). Electrochemical Vanillin Determination on Gold Nanoparticles Modified Multiwalled Carbon Nanotube Electrode, Journal of Science and Engineering, 20 (59), 461-470.

Chen, L., Chaisiwamongkhol, K., Chen, Y. \& Compton, R. G. (2019). Rapid Electrochemical Detection of Vanillin in Natural Vanilla, Electroanalysis, 31 (6), 1067-1074.

D'Souza, O. J., Mascarenhas, R. J., Satpati, A. K., Mane, V. \& Mekhalif Z. (2017). Application of a Nanosensor Based on MWCNT-Sodium Dodecyl Sulphate Modified Electrode for the 
Analysis of a Novel Drug, Alpha-Hydrazinonitroalkene in Human Blood Serum, Electroanalysis 29 (7), 1794-1804.

Denuault, G., Mirkin, M. V. \& Brad, A. J. (1991). Direct determination of diffusion coefficients by chronoamperometry at microdisk electrodes, Journal of Electroanalytical Chemistry 308, 27-38.

Dilgin, D. G. (2019). Voltammetric Determination of Vanillin Using a Pretreated Pencil Graphite Electrode, Akademik Glda, 17 (1), 1-8.

Durán, G.M., \& Contento, A.M. \& Ríos., Á. (2015). $\beta$-Cyclodextrin coated CdSe/ZnS quantum dots for vanillin sensoring in food samples, Talanta, 131, 286-291.

Durán, G.M., Llorent-Martínez, E.J., Contento, A.M. \& Ríos., Á. (2018). Determination of vanillin by using gold nanoparticle-modified screen-printed carbon electrode modified with graphene quantum dots and Nafion, Microchimica Acta, 185, 204.

Erady, V., Mascarenhas, R. J. \& Satpati, A. K. (2020). Highly efficient and selective quantification of vanillin in food, beverages and pharmaceuticals using surfactant modified carbon paste sensor, Sensors International, 1, 100023.

Fu, L., Xie, K., Wu, D., Wang, A., Zhang, H. \& Ji, Z. (2020). Electrochemical determination of vanillin in food samples by using pyrolyzed graphitic carbon nitride, Materials Chemistry and Physics, 242, 122462.

Gao, J., Yuan, Q., Ye, C., Guo, P., Du, S., Lai, G., Yu, A., Jiang, N., Fu, L., Lin, C. T. \& Chee, K. W. A. (2018). Label-Free Electrochemical Detection of Vanillin through Low-Defect Graphene Electrodes Modified with Au Nanoparticles, Materials, 11 (4), 489.

Gupta, V. K., Karimi-Maleh, H., Agarwal, S., Karimi, F., Bijad, M., Farsi, M., Shahidi, S. A. (2018). Fabrication of a Food Nano-Platform Sensor for Determination of Vanillin in Food Samples, Sensors, 18, 2817.

Isac-García, J., Dobado, J. A., Calvo-Flores, F. G. \& Martínez-García, H. (2016). Chapter 11 - Microscale Experiments. In Isac-García, J., Dobado, J. A., Calvo-Flores, F. G. \& Martínez-García, H. (1 ${ }^{\text {st }}$ Eds.), Experimental Organic Chemistry (371-408). Academic press. 
Kalaiyarasi, J., Meenakshi, S., Pandian, K. \& Gopinath, Subash C. B. (2017). Simultaneous voltammetric determination of vanillin and guaiacol in food products on defect free graphene nanoflakes modified glassy carbon electrode, Microchim Acta, 184, 2131-2140.

Research And Markets, The World's Largest Market Research Store (2019). Vanilla and Vanillin Market: Global Industry Trends, Share, Size, Growth, Opportunity and Forecast 2019-2024, IMARC Group, Report ID: 4752325.

Karimi-Maleh H., Karimi F., Alizadeh M., Sanati A. L. (2020). Electrochemical Sensors, a bright future in the fabrication of portable kits in analytical systems, Chemical record, 20, 682-69

Kroto, H. W. (1987). The stability of the fullerenes $\mathrm{C}_{\mathrm{n}}$, with $\mathrm{n}=24,28,32,36,50,60$ and 70 , Nature, 329, 529-531.

Kutty, M., Settu, R. I., Chen, S. M., Chen, T. W., Tseng, T. W., Hatamleh, A. A., Yu, J., Yu, R. \& Huang, C. C. (2019). An Electrochemical Detection of Vanillin Based on Carbon Black Nanoparticles Modified Screen Printed Carbon Electrode, International Journal of Electrochemical Science, 14, 5972-5983.

Manasa, G., Ronald, J. M., Basavanakote, M. B. (2019). Sensitively-selective determination of Propyl Paraben preservative based on synergistic effects of polyaniline-zinc-oxide nanocomposite incorporated into graphite paste electrode, Colloids and Surfaces B:

Biointerfaces, 184, 110529.

Mazloum-Ardakani, M., Ahmadi, S. H., Safaei Mahmoudabadi, Z. \& Khoshroo, A. (2016). Nano composite system based on fullerene-functionalized carbon nanotubes for simultaneous determination of levodopa and acetaminophen, Measurement, 91, 162-167.

Miyazawa K. (2009). Synthesis and properties of fullerene nanowhiskers and fullerene nanotubes. Journal of nanoscience and nanotechnology, 9 (1), 41-50.

Mohan, H.K.S.V., Chee, W.K., Li, Y., Nayak, S., Poh, C. L., Thean, A. V. Y. (2019). A highly $\underline{\text { sensitive graphene oxide based label-free capacitive aptasensor for vanillin detection, }}$ Materials \& Design, 186, 108208.

Murtada, K., Jodeh, S., Zougagh, M. \& Ríos, Á. (2018). Development of an Aluminium Doped $\underline{\mathrm{TiO} 2}$ Nanoparticles-modified Screen Printed Carbon Electrode for Electrochemical Sensing of Vanillin in Food Samples, Electroanalysis, 30, 969. 
Nasuno, R., Shino, S., Yoshikawa, Y., Yoshioka, N., Sato, Y., Kamiya, K. \& Takag H. (2020). Detection system of the intracellular nitric oxide in yeast by HPLC with a fluorescence detector, Analytical Biochemistry, 598, 113707.

Ning, J., He, Q., Luo, X., Wang, M., Liu, D., Wang, J., Liu, J. \& Li, G. (2018). Rapid and Sensitive

Determination of Vanillin Based on a Glassy Carbon Electrode Modified with $\mathrm{Cu} 2 \mathrm{O}-$

Electrochemically Reduced Graphene Oxide Nanocomposite Film, Sensors, 18 (9), 2762.

Pajkossy, T. \& Jurczakowski, R. (2017). Electrochemical impedance spectroscopy in interfacial studies, Curruent Opinion in Electrochemistry, 1 (1), 53-58.

Pan, Y., Liu, X., Zhang, W., Liu, Z., Zeng, G., Shao, B., Liang, Q., He, Q., Yuan, X., Huang, D. \&

Chen, M. (2020). Advances in photocatalysis based on fullerene C60 and its derivatives:

Properties, mechanism, synthesis, and applications, Applied Catalysis B:

Environmental, 265, 118579.

Pilehvar, S. \& Wael, K. D. (2015). Recent Advances in Electrochemical Biosensors Based on FNTserene-C60 Nano-Structured Platforms, Biosensors, 5 (4), 712-735.

Ramesh, M. \& Muthuraman, A. (2018). Flavoring and Coloring Agents: Health Risks and Potential Problems, Natural and Artificial Flavoring Agents and Food Dyes, Handbook of Food Bioengineering, 1-28.

Randviir, E. P. \& Banks, C. E. (2013). Electrochemical impedance spectroscopy: an overview of bioanalytical applications, Analytical Methods, 5, 1098-1115.

$\underline{\text { Rao, R. V. K., Karthik, P. S., Abhinav, V. K., Lin, Z., Myint, M. T. Z., Nishikawa, T., Hada, M., }}$ Yamashita, Y., Hayashi, Y., \& Singh, S. P. (2016). Self-assembled C60 fullerene cylindrical nanotubes by LLIP method. In 16th International Conference on Nanotechnology - IEEE NANO, Institute of Electrical and Electronics Engineers, [7751386], 303-306.

Raril, C. \& Manjunatha, J.G. (2020). A simple approach for the electrochemical determination of vanillin at ionic surfactant modified graphene paste electrode, Microchemical journal, 154, $\underline{104575 .}$

Serjeant, E. P. \& Dempsey B. (1979). Ionisation constants of organic acids in aqueous solution, International union of pure and applied chemistry, IUPAC Chemical Data Serie, 23, 989. 
Sherigara, B. S., Kutner, W. \& Souza, F. D. (2003). Electrocatalytic Properties and Sensor Applications of fullerenes and Carbon Nanotubes, Electroanalysis, 15 (9), 753-772.

Shrivastava, A. \& Gupta, V. B. (2011). Method for the determination of limit of detection and limit of quantification of the analytical methods, Chronicles of Young Scientists, 2 (1), 21-25.

Shu, M., Man, Y., Ma, H., Luan, F., Liu, H. \& Gao, Y. (2016). Determination of Vanillin in Milk Powder by Capillary Electrophoresis Combined with Dispersive Liquid-Liquid Microextraction, Food Analytical Methods, 9, 1706-1712.

Sinha, A. K., Sharma, U. K. \& Sharma, N. (2008). A comprehensive review on vanilla flavor: Extraction, isolation and quantification of vanillin and others constituents, International Journal of Food Sciences and Nutrition, 59 (4), 299-326.

Sivakumar, M., Sakthivel, M. \&. Chen, S.-M. (2017). Simple synthesis of cobalt sulfide nanorods for efficient electrocatalytic oxidation of vanillin in food samples, J. Colloid Interface Sci. $\underline{490,719-726 .}$

Tabanligil Calam, T. (2020). Voltammetric determination and electrochemical behavior of vanillin based on 1H-1,2,4-triazole-3-thiol polymer film modified gold electrode, Food Chemistry, 328, 127098.

Younes, M., Aggett, P, Aguilar, F., Crebelli, R., Dusemund, B., Filipic, M., Jose Frutos, M., Galtier, P., Gundert-Remy, U., Georg Kuhnle, G., Lambre, C., Leblanc, J. C., Therese Lillegaard, I., Moldeus, P., Mortensen, A., Oskarsson, A., Stankovic, I., WaalkensBerendsen, I., Woutersen, R. A., Wright, M., Tobback, P., Smeraldi, C. \& Gott, D. (2018). $\underline{\text { Safety of orthosilicic acid-vanillin complex (OSA-VC) as a novel food ingredient to be used }}$ in food supplements as a source of silicon and bioavailability of silicon from the source, EFSA Journal, $16(1), 5086$.

Zhang, H., Fan, L. \& Yang, S. (2006). Significantly Accelerated Direct Electron-Transfer Kinetics of Hemoglobin in a C60-MWCNT Nanocomposite Film, Chemistry-A European Journal, 12 (27), 7161-7166.

Zhao, J., Xia, H., Yu, T., Jin, L., Li, X., Zhang, Y., Shu, L., Zeng, L. \& He, Z. (2018). A colorimetric assay for vanillin detection by determination of the luminescence of o-toluidine condensates, PLoS ONE 13(4): e0194010 
Zhu, H., Wu, W., Zhang, H., Fan, L. \& Yang, S. (2009). Highly Selective and Sensitive Detection of Dopamine in the Presence of Excessive Ascorbic Acid Using Electrodes Modified with C60-Functionalized Multiwalled Carbon Nanotube Films, Electroanalysis, 21 (24), 26602666.

\section{Figure captions}

Figure 1. Graphical presentation of f-MWCNTs-FNTs/ CPE sensor fabrication.

Figure 2. SEM images for (A) graphite (x10.000), (B) f-MWCNTs-FNTs / CPE (x10.000), (C) FNTs (x10.000), (D) FNTs (x50.000), (E) MWCNT (x30.000) and (F) f-MWCNT (x30.000).

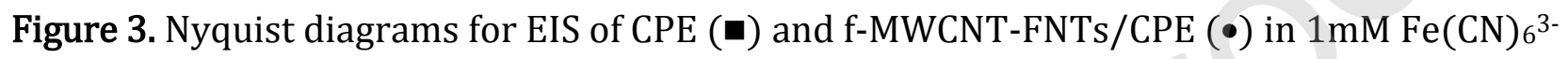
and BRS $0.04 \mathrm{M}$ at $\mathrm{pH}=7$; frequency range $0.001-10000 \mathrm{~Hz}$, potential amplitude $10 \mathrm{mV}$

Figure 4. Cyclic voltammograms at (1) CPE without VAN, and with $10^{-5} \mathrm{~mol}$. $\mathrm{L}^{-1} \mathrm{VAN}$ at (2) CPE, (3) f-MWCNTs/ CPE and (4) f-MWCNTs-FNTs/CPE in BRS $0.04 \mathrm{M}$ (pH = 7); 20 mV.s ${ }^{-1}$.

Figure 5. (A) Effect of $\mathrm{pH}$ on the peak current oxidation of VAN with different $\mathrm{pH}$ value (5 to 9) at the f-MWCNTs-FNTs/ CPE in BRS 0.04 M (pH = 7) at $20 \mathrm{mV} . \mathrm{s}-1$. (B) Corresponding plot of the oxidation peak potential of VAN versus $\mathrm{pH}$.

Figure 6. (A) The effect of different scan rates (10 to $\left.80 \mathrm{mV} \cdot \mathrm{s}^{-1}\right)$ and (B) the effect of accumulation time on the oxidation peak current of $10^{-6}$ mol.L-1 VAN at the f-MWCNTs-FNTs/ CPE in BRS 0.04M (pH = 7).

Figure 7. (A) Cyclic voltammograms of VAN from $5 \times 10^{-8}$ to $1 \times 10^{-4} \mathrm{~mol} \mathrm{~L}^{-1}$ at $\mathrm{f}-\mathrm{MWCNTs}-\mathrm{FNTs} /$ CPE in BRS 0.04M ( $\mathrm{pH}=7$ ), Insert: from $5 \times 10^{-8}$ to $9 \times 10^{-6} \mathrm{~mol} \mathrm{~L}^{-1}$. (B, C) Calibration curves of VAN concentrations against peak current from $5 \times 10^{-8}$ to $9 \times 10^{-6} \mathrm{~mol} \mathrm{~L}^{-1}$ and from $1 \times 10^{-5}$ to $1 \times 10^{-4} \mathrm{~mol} \mathrm{~L}^{-1}$, respectively.

Figure 8. The relative peak current response of $1 \mu \mathrm{M}$ VAN in the presence of some potential interfering substances at the f-MWCNTs-FNTs/ CPE in BRS 0.04M (pH = 7).

Figure 9. The study of stability of the f-MWCNTs-FNTs/ CPE for the relative peak current response of $1 \mu \mathrm{M}$ VAN in ten days of storage. 
Figure 1.

Preparation of the electrode

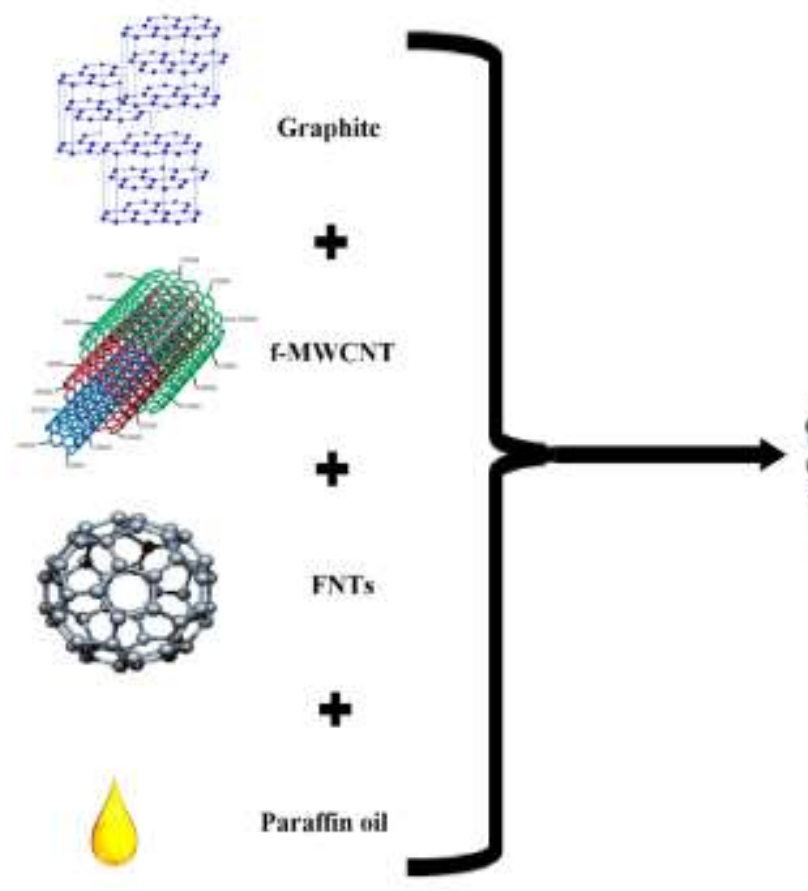

Electrochemical detection

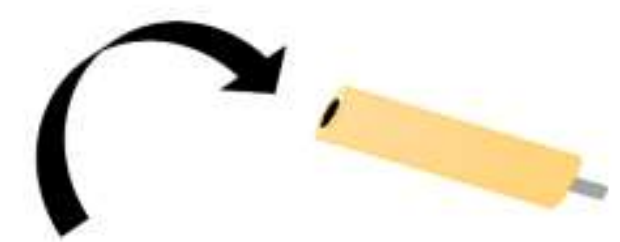

f-MWCNT-FNTs/CPE

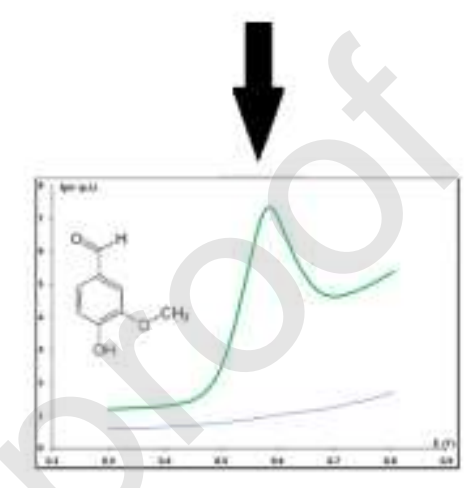


Figure 2.

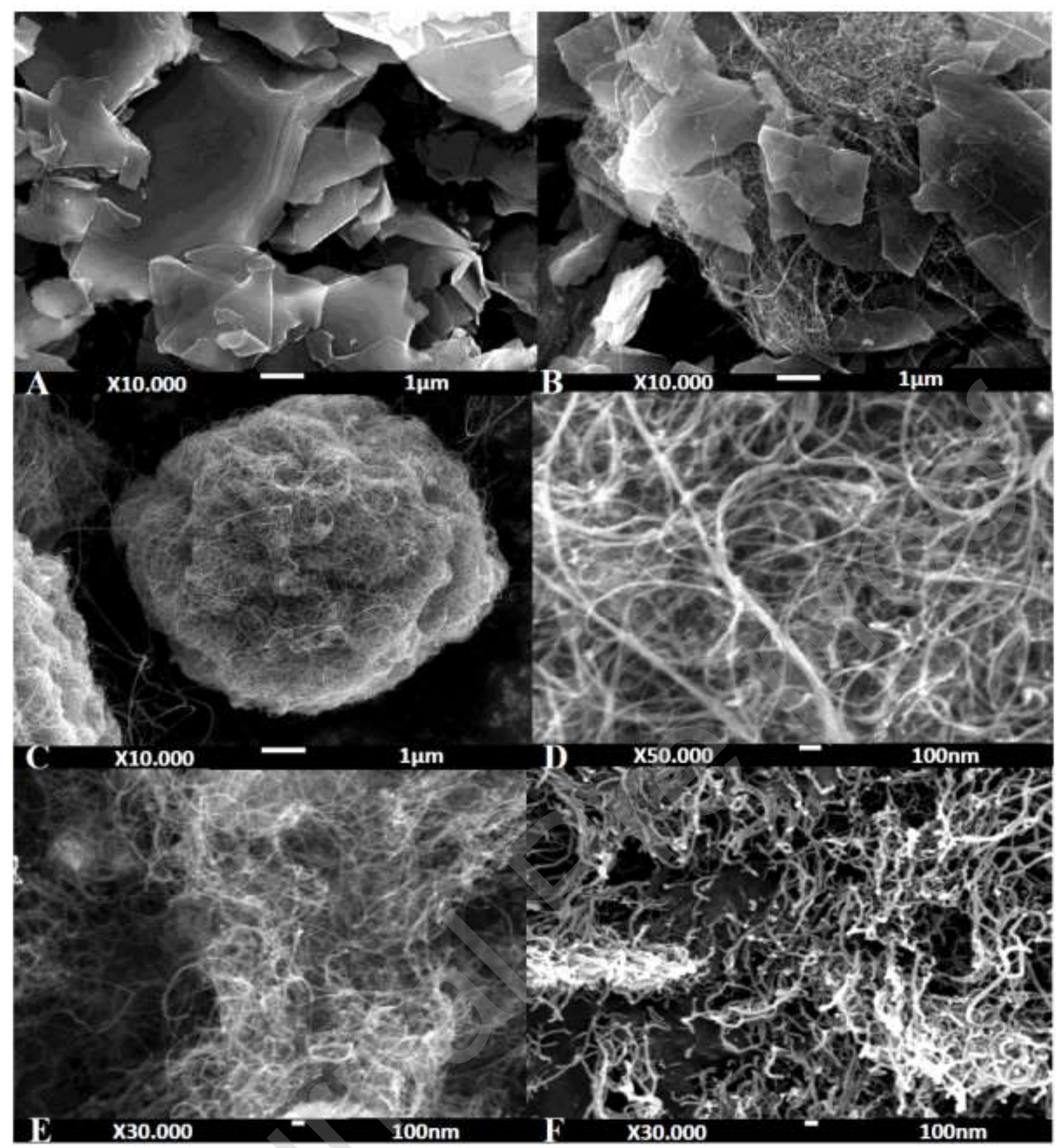


Figure 3.

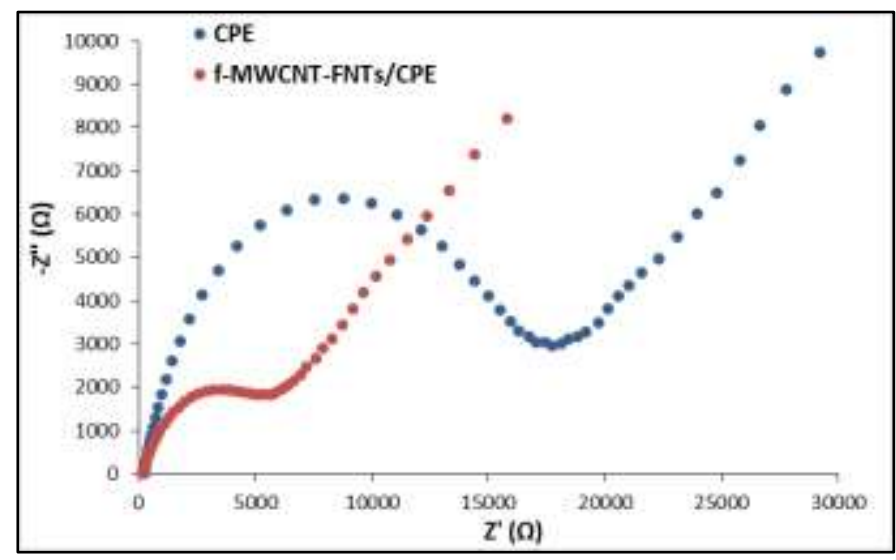

Figure 4.

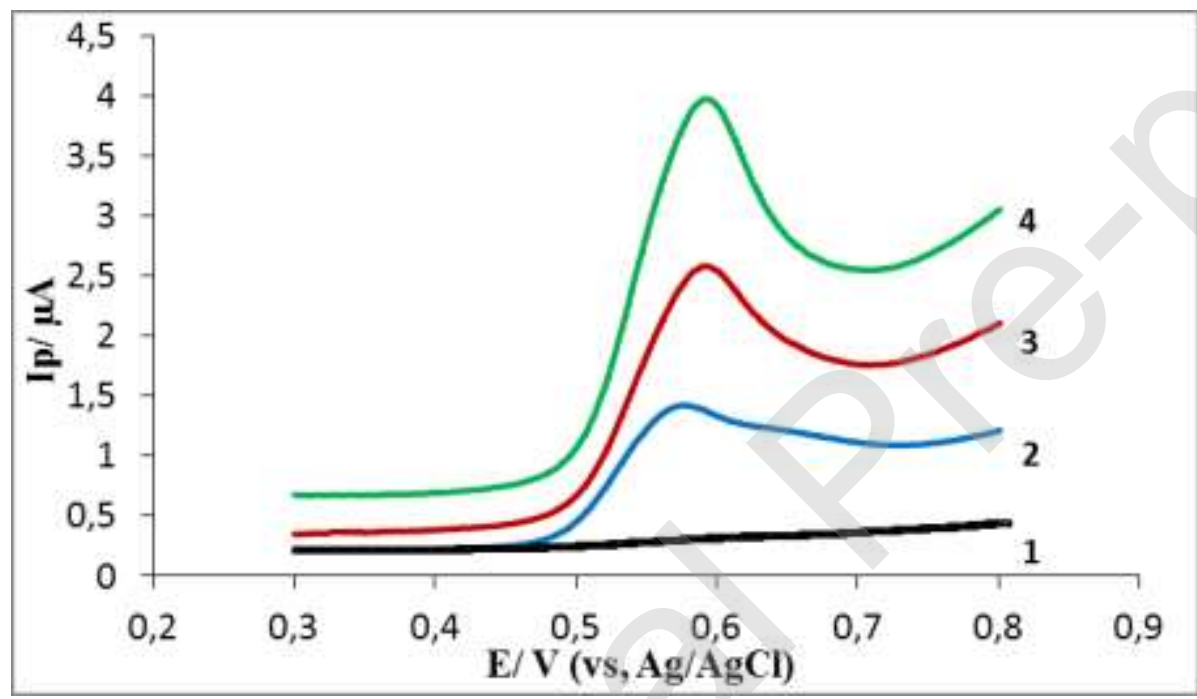

Figure 5.

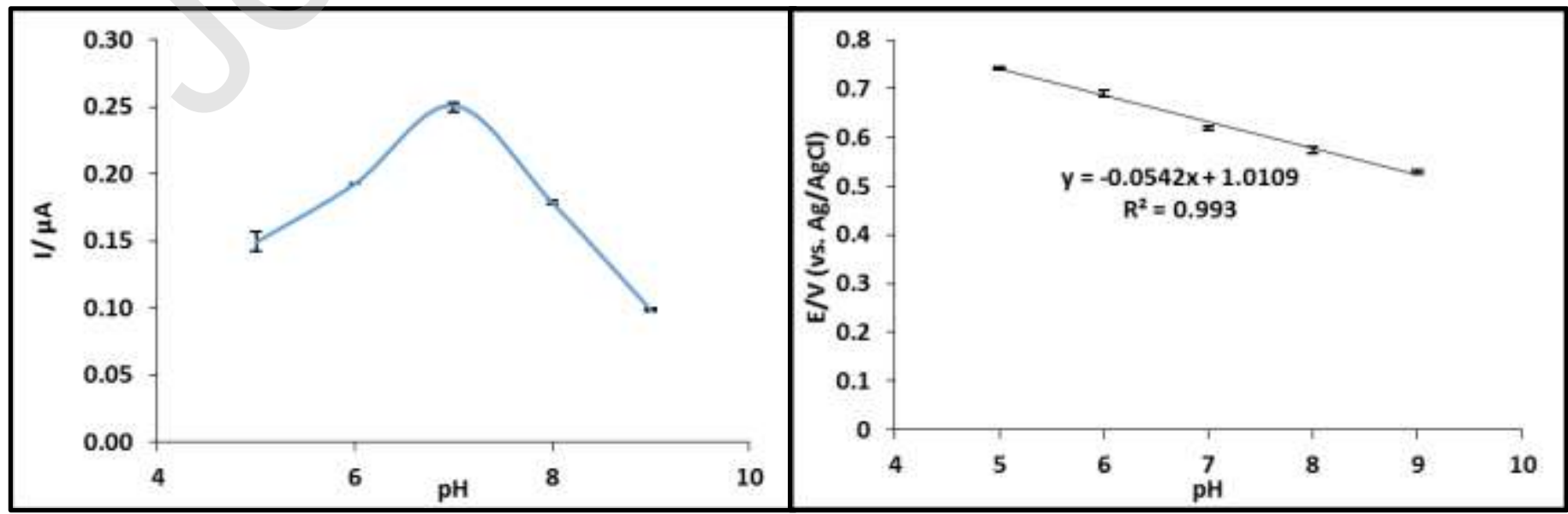


Figure 6.

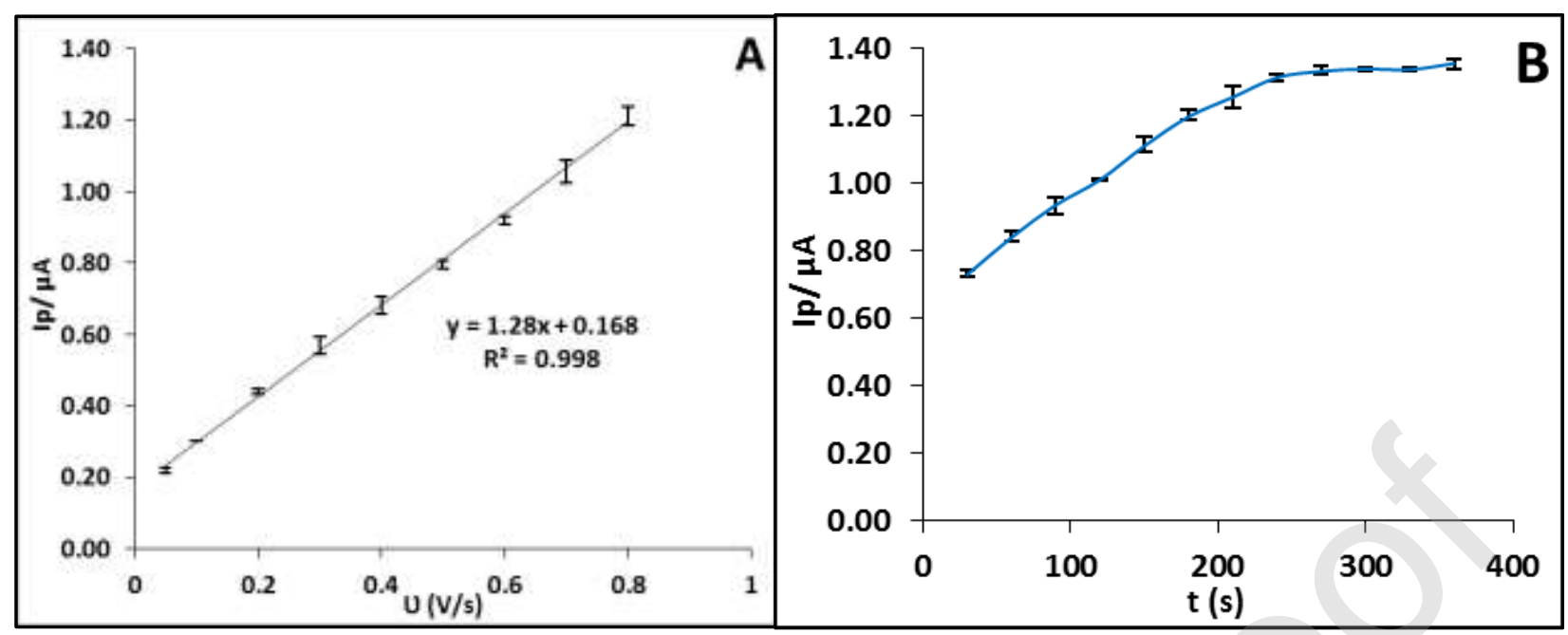

Figure 7.

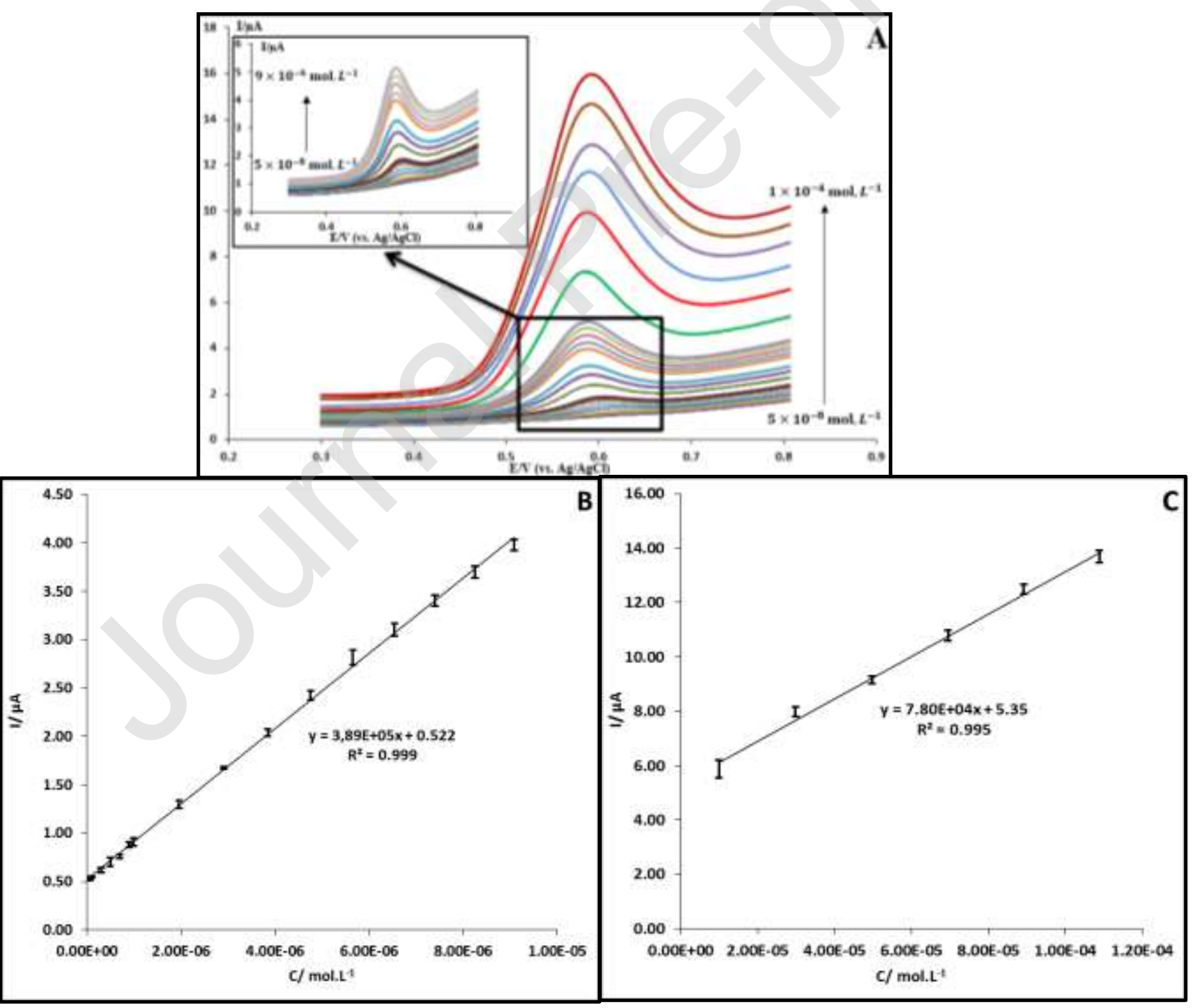


Figure 8.

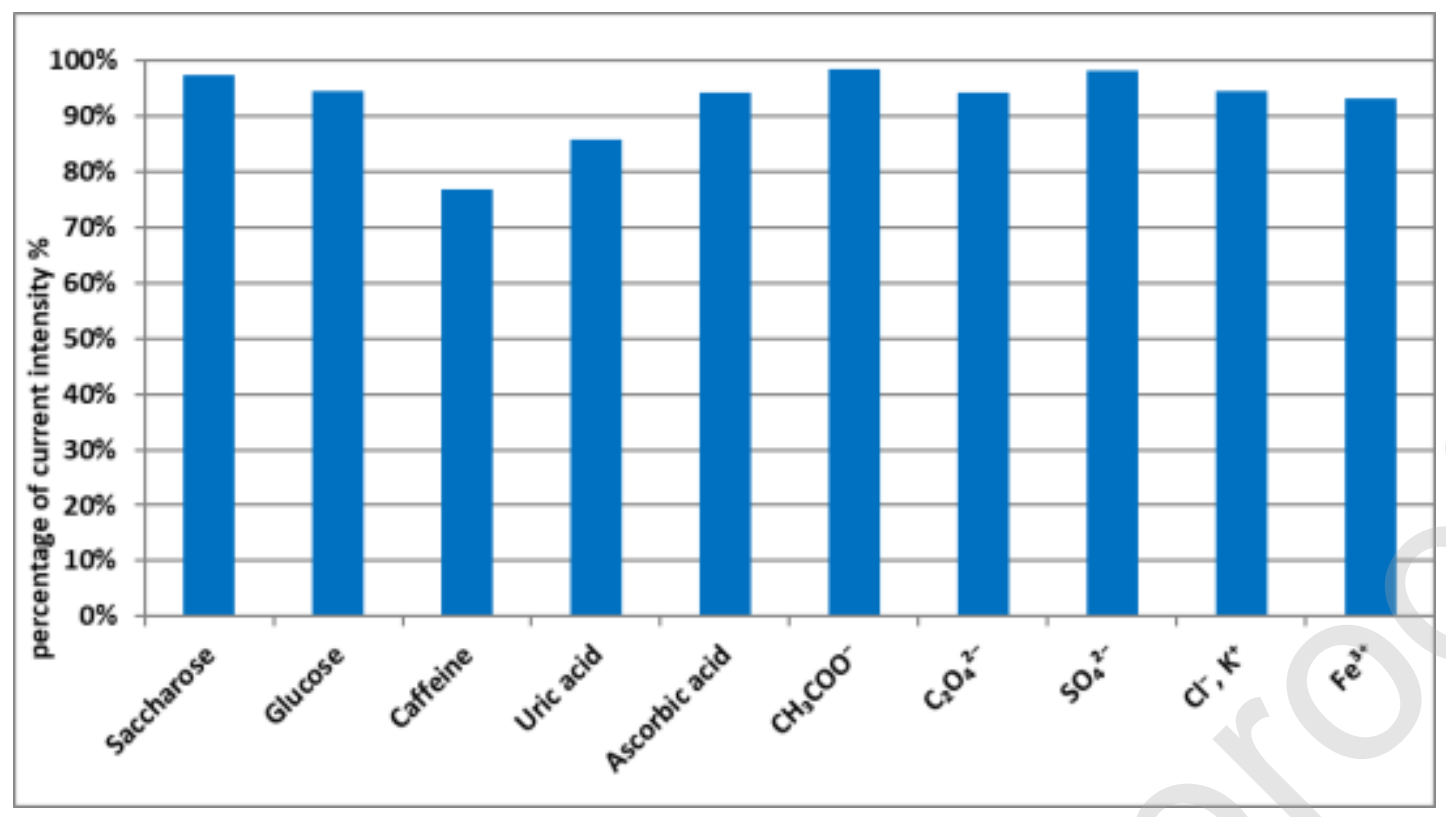

Figure 9.

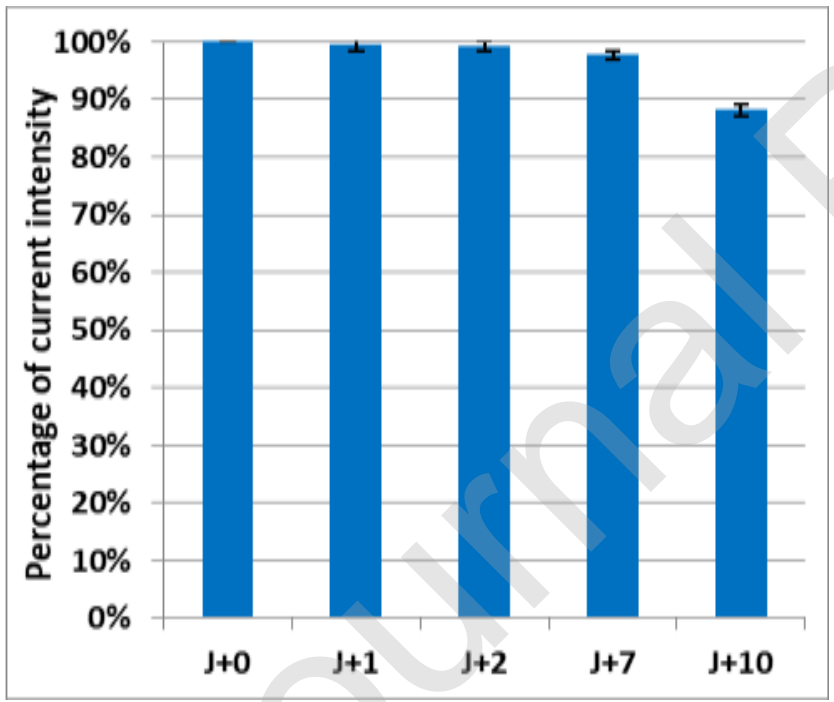


Table captions

Table 1. Comparison with this work of previously reported VAN analysis with electrochemical sensor

\begin{tabular}{|c|c|c|c|}
\hline Electrode & Linear range $\left(\mathrm{mol}^{-\mathrm{L}^{-1}}\right)$ & $\begin{array}{l}\text { Detection limit } \\
\left(\mathrm{mol} . \mathrm{L}^{-1}\right)\end{array}$ & Ref. \\
\hline Au-MWCNTs/GCE ${ }^{1}$ & $\begin{aligned} & 7 \times 10^{-8} \text { to } 6.5 \\
& \times 10^{-6} \text { and } \\
& 7 \times 10^{-6} \text { to } 7.5 \times 10^{-5}\end{aligned}$ & $3.8 \times 10^{-8}$ & $\begin{array}{l}\text { Ceylan Koçak et } \\
\text { al., } 2018\end{array}$ \\
\hline p-PGE ${ }^{2}$ & $5 \times 10^{-7}$ to $1 \times 10^{-5}$ & $1.6 \times 10^{-7}$ & $\begin{array}{l}\text { Dilgin et al., } \\
2019\end{array}$ \\
\hline CPE/NiO-SWCNTs/BPrPF ${ }_{6}{ }^{3}$ & $1 \times 10^{-8}$ to $3.5 \times 10^{-4}$ & $4 \times 10^{-9}$ & Gupta et al., 2018 \\
\hline CB/SPCE ${ }^{4}$ & $5 \times 10^{-5}$ to $4.5 \times 10^{-4}$ & $3.9 \times 10^{-8}$ & Kutty et al., 2019 \\
\hline CNT-SPE 5 & $2.5 \times 10^{-6}$ to $7.5 \times 10^{-4}$ & $1.03 \times 10^{-6}$ & Chen et al., 2019 \\
\hline $\mathrm{C}_{3} \mathrm{~N}_{4} / \mathrm{GCE}^{6}$ & $\begin{array}{c}2 \times 10^{-8} \text { to } 1 \times 10^{-5} \text { and } \\
1.5 \times 10^{-5} \text { to } 2 \times 10^{-4}\end{array}$ & $7 \times 10^{-9}$ & Fu et al., 2020 \\
\hline BGPE $^{7}$ & $\begin{array}{c}4 \times 10^{-6} \text { to } 1.5 \\
\times 10^{-5} \text { and } \\
2 \times 10^{-5} \text { to } 7 \times 10^{-5}\end{array}$ & $1.29 \times 10^{-6}$ & Raril et al., 2020 \\
\hline T3T-Au electrode ${ }^{8}$ & $1 \times 10^{-7}$ to $1.13 \times 10^{-5}$ & $4 \times 10^{-8}$ & $\begin{array}{l}\text { Tabanligil Calam, } \\
2020\end{array}$ \\
\hline f-MWCNTs-FNTs/ CPE & $\begin{array}{c}5 \times 10^{-8} \text { to } 9 \times 10^{-6} \text { and } \\
1 \times 10^{-5} \text { to } 1 \times 10^{-4}\end{array}$ & $3.5 \times 10^{-8}$ & This work \\
\hline
\end{tabular}

${ }^{1}$ Gold nanoparticles modified multi-walled carbon nanotubes glassy carbon electrode, ${ }^{2}$ Preoxidized Pencil Graphite Electrode, ${ }^{3}$ Carbon Paste Electrode modified with $\mathrm{NiO}$ decorated single wall carbon nanotubes and 1-butylpyridinium hexafluorophosphate, ${ }^{4}$ Carbon Black Nanoparticles Modified Screen Printed Carbon Electrode, ${ }^{5}$ Multi-walled carbon nanotube screen-printed electrode, ${ }^{6}$ Pyrolyzed graphitic carbon nitride electrode, ${ }^{7}$ Bare graphene paste electrode, ${ }^{8} 1 \mathrm{H}$ 1,2,4-triazole-3-thiol polymer film modified gold electrode. 
Table 2. Validation of the electrochemical method: (A) Study of repeatability and reproducibility of detection for different VAN concentrations at f-MWCNTs-FNTs/ CPE in BRS 0.04M (pH = 7); preconcentration time under stirring 300 s; 20 mV.s ${ }^{-1}$. (B) Determination of VAN mass fraction in different real commercial sugar vanilla samples with electrochemical and UPLC/UV methods

Table 2-A

\begin{tabular}{|l|l|l|}
\hline \multirow{2}{*}{ VAN concentration $(\boldsymbol{\mu M})$} & \multicolumn{2}{|l|}{ Determination of repeatability \& reproducibility } \\
\cline { 2 - 3 } & Repeatability of $\boldsymbol{I}_{\boldsymbol{p}}$ RSD\% $*$ & Reproducibility of $\boldsymbol{I}_{\boldsymbol{p}}$ RSD\% ** \\
\hline $\mathbf{0 . 1}$ & $2.1 \%$ & $2.1 \%$ \\
\hline $\mathbf{1}$ & $6.7 \%$ & $5.8 \%$ \\
\hline $\mathbf{1 0}$ & $2.9 \%$ & $1.1 \%$ \\
\hline
\end{tabular}

Table 2-B

\begin{tabular}{|c|c|c|c|c|c|c|}
\hline \multirow{3}{*}{$\begin{array}{l}\text { Sugar } \\
\text { samples }\end{array}$} & \multicolumn{4}{|c|}{ Determination of VAN mass fraction mg.g ${ }^{-1}$} & \multirow{3}{*}{$\begin{array}{l}\text { Recovery } \\
(\%)\end{array}$} & \multirow{3}{*}{$\begin{array}{l}\text { Relative } \\
\text { error } \\
(\%)\end{array}$} \\
\hline & \multicolumn{2}{|c|}{ Electrochemical method $(\mathrm{n}=3)$} & \multicolumn{2}{|c|}{ UPLC Analytical method $(\mathrm{n}=3)$} & & \\
\hline & $\begin{array}{l}\text { Mean } \pm \text { confidence } \\
\text { interval } * * *\end{array}$ & $\mathrm{RSD} \%$ & $\begin{array}{l}\text { Mean } \pm \text { confidence } \\
\text { interval } * * *\end{array}$ & RSD \% & & \\
\hline E1 & $3.91 \pm 0.22$ & 3.0 & $3.67 \pm 0.02$ & 0.3 & 106.5 & 6.5 \\
\hline $\mathbf{E 2}$ & $4.79 \pm 0.92$ & 10.4 & $4.61 \pm 0.02$ & 0.2 & 103.9 & 3.9 \\
\hline $\mathbf{E 3}$ & $3.64 \pm 0.23$ & 3.3 & $3.61 \pm 0.01$ & 0.1 & 100.8 & 0.8 \\
\hline E4 & $2.88 \pm 0.34$ & 6.5 & $2.76 \pm 0.02$ & 0.7 & 104.3 & 4.3 \\
\hline
\end{tabular}

$* \mathrm{n}=3, * * \mathrm{n}=2, * * *$ Confidence interval for $\propto=0.5$ 